Article

\title{
Tourists' Risk Perception and the Use of Mobile Devices in Beach Tourism Destinations
}

\author{
Francesc González-Reverté * (i), Pablo Díaz-Luque * (i), Joan Miquel Gomis-López * \\ and Soledad Morales-Pérez * \\ Faculty of Economics and Business, Universitat Oberta de Catalunya, Barcelona 08035, Spain \\ * Correspondence: fgonzalezre@uoc.edu (F.G.-R.); pdiazlu@uoc.edu (P.D.-L.); jgomisl@uoc.edu (J.M.G.-L.); \\ smoralespe@uoc.edu (S.M.-P.)
}

Received: 31 October 2017; Accepted: 30 January 2018; Published: 6 February 2018

\begin{abstract}
The perceived risk of tourists' use of smartphones is a key issue in shaping the tourist experience in terms of sustainability, as it can affect the behaviour of tourists and influence their satisfaction with that experience. However, little empirical research exists on the relationship between tourists' risk perception and the perceived value of mobile device usage. This paper measures the association between tourists' perceived risk of mobile device usage and several variables that demonstrate the perceived usefulness of mobile devices: utility, hedonic value and future intention of use. A survey on tourists' use of smartphones was conducted in 2016 and, by means of a cluster analysis, four groups of tourists were identified with significant differences in their perception of the risk and use value of smartphones. Differences between tourists suggest that a single digital tourist profile does not exist and that tourism destinations and smart tourism DMOs (destination marketing organisations) should include risk perception in their management agenda. This will allow them to achieve a better understanding of tourist behaviour and to adapt the commercialisation of tourism products and services to a wide range of tourism needs. In addition, four regression models were applied to measure the association between the risk and perceived usefulness of mobile devices. On the one hand, dependence on mobile devices was associated positively with the perceived usefulness of mobile devices. On the other hand, the tourists surveyed saw privacy risk as having a major negative impact on the tourist experience, although it did not affect their perceived utility value and future use of mobile devices. Smart tourism destination managers should bear in mind that privacy risk issues related to the use of mobile devices must be integrated into an ethical perspective when marketing a destination.
\end{abstract}

Keywords: perceived risk; smartphone; utilitarian value; hedonic value; future use

\section{Introduction}

The use of mobile devices has become so widespread that it is now a standard resource for tourists on holiday. Thus, knowing the elements that influence tourist behaviour regarding these devices, mostly smartphones, is not only a very important factor to provide an adequate management response at a tourist destination, but also for the viability of tourist businesses that introduce technological components into their business models. Tourists' behaviour and their role as co-producers of experiences are conditioned by the way they use technology and mobile phones [1-3]. In addition, the use of mobile phones is especially relevant in destinations that take a proactive approach to the introduction of intelligent tourism elements and attractions that have a strong dependence on technology. The improvement of connectivity and the use of mobile phones make destinations more accessible to tourists [4], contributing to the co-creation of value in the tourist experience $[5,6]$ and stimulating open innovation [7]. Thus, smart tourism destinations and the new tourism business 
models that incorporate them have a strong relationship with their visitors' use of mobile phones. Consequently, tourist destination managers need precise information that allows them not only to better understand the entire situation, but also to be able to take more accurate decisions regarding tourists' behaviour at the destination. In this sense, a crucial subject under study is knowledge of the risk associated with the use of mobile phones as one of the elements that can influence tourists' behaviour and satisfaction with the tourist experience.

At a tourist destination, the context in which information is captured through mobile phones favours risks (monitoring, location data, etc.) being taken more unconsciously and vulnerability in terms of privacy intrusion $[8,9]$. Although this is a very important element of debate in understanding the role of digital tourists, the relationship between the perception of risk and the use of mobile phones on holidays is a field rarely studied. The debate surrounding the constraints, limits and barriers to the use of mobile phones in tourist destinations is a fundamental element for their efficient management. However, there is limited empirical analysis and few cases of study.

To further go deeply into the debate on this topic, our research aims to make an empirical contribution in order to provide evidence that will allow us to better understand how the perceived risk of mobile phones contributes to modifying the perceived utility received and the hedonic value of these instruments. The study first aims to determine whether there are differences in perception of risk associated with the use of mobile phones among tourists and to determine the variables that explain this. Second, it will consider two facets of risk and uncertainty regarding the use of mobile phones as perceived by tourists-privacy and dependence-to distinguish different effects of smartphone use derived from different types of risk. Finally, we will analyse the consequences the perception of risk has regarding tourists' use of mobile phones in relation to the perceived utility value and hedonic value as well as tourists' intentions to use mobile phones in the future.

The study was carried out through a survey developed simultaneously in two mass tourism destinations on the Catalan coast, Sitges and Calella, where there is a good representation of the diversity of tourist profiles interested in beach destination holidays. In this sense, the contributions that have been obtained can be easily transferred to other territorial contexts. The main goal of this study is to analyse whether different perceived risk impacts linked to the use of mobile devices exist and if these differences vary between groups of tourists. From a management point of view, the responses can be formulated to solve ethical problems that smart destinations face when developing marketing and planning strategies. This is a particularly sensitive issue when destinations use personal data to plan and design tourism marketing strategies and personalised offers targeting tourists and visitors.

\subsection{The Use of Mobile Devices and the Perception of Risk among Tourists}

In recent decades, tourists have greatly increased their acceptance of and trust in the use of mobile phones when on holiday. Some authors even refer to smartphone technology as a catalyst of tourist activity [10] and point out the existence of a digital tourist profile that differs from traditional tourists [11]. Tourists profusely use mobile devices and their applications. Thus, this may have consequences for their behaviour when they are on holiday at a destination [12]. In addition, this also conditions the way they search for information about tourism products [13]. According to Wang, Xiang and Fesenmaier, tourists' interest in mobile phones can be explained by a combination of functional aspects (they facilitate the search for useful information about the destination during the visit and allow tourists to assess the destination aesthetically before visiting it) and social aspects (they allow tourists to make innovative trips, reinforce the hedonic aspects of travel and contact with local culture, and allow them to reproduce and transfer their experience socially) [14].

The integration of mobile phones into tourists' travel experience can be interpreted through the interaction of different factors. Mobile phones are understood by tourists as a resource that supports their experience through technologies that allow location awareness and context awareness [15], augmented reality [16], or applications that contribute to an improved tourist experience and access to new possibilities, among others $[14,17]$. Tourists' use of smartphones goes beyond the functionalities 
that this offers and includes an equally significant social value. Mobile phones and social networks (social media) are not just technological objects used by tourists; they also become tools that are part of tourists' social life [18]. Access to the Internet through mobile phones allows tourists to keep their presence on social media active and it becomes an important part of the tourist experience [19]. Tourists keep in touch with their social networks long-distance using smartphones, social media, free Wi-Fi infrastructure and improved broadband connections for mobile phones. The increase in social interaction between people and their own social networks has been interpreted through the concept of network individualism [20].

Tourists have a positive attitude regarding smartphones due to the opportunities they provide for mediation and immersion in the experience, obtaining real-time information, and interacting with social networking communities. The functional value of mobile phones as perceived by tourists contributes to their identification as a support tool for the travel experience. This not only increases their use and interaction time throughout their visit as tourists, but also their dependence. Meanwhile, it also relaxes tourists' perception of the risks associated with smartphone use. The increase in the interaction between tourists and mobile phones has also begun to be studied from the point of view of the emotional and affective relationships which some authors call "passionate use" [21-24].

Research on the applications of tourism technology has primarily focused on the benefits derived from the adoption of technology among tourists. However, much still needs to be analysed to understand the barriers and limitations to the use of technology in tourism activity. This study seeks to help bridge this gap based on an analysis of tourists' perceived risk of the use of smartphones and its influence on smartphone use during their holidays as well as their propensity for future use.

Extensive academic literature exists on the analysis of consumers' perceived risk and its effects on tourist destinations. In general terms, the emergence of risk is associated with the lack of knowledge about a phenomenon in such a way that it generates a degree of uncertainty and ignorance about the possible consequences of carrying out an action [25]. In the area of tourists' holiday decision-making, there is agreement that perceived risk can cause tourists to change their minds when choosing a destination in which to spend their holidays. In cases where the perceived situation is considered unacceptable or undesirable, a modification of the previously planned actions may be carried out [26]. This general framework is not directly applicable to our study, since it is only interested in determining how tourists behave once they have already reached their destination in regard to mobile phone use risk perception, and not as a factor in the holiday destination decision-making process. However, it does serve as an initial starting point, as it shows that any perceived risk is likely to lead to changes in tourist behaviour.

Although the concepts of risk and uncertainty are often used indistinctly [27], there are differences depending on the level of information and knowledge that a person has on a particular phenomenon. Risk refers to the calculation of the probability of a negative event occurring $[28,29]$. Thus, it involves uncertainty regarding the knowledge that is available. On the other hand, uncertainty refers to the partial knowledge that a person has of a phenomenon at the moment in which she or he makes a decision. Uncertainty, therefore, is related to the unknown aspects that may appear due to the influence of exogenous elements or other factors that are not known by the person who has to make a decision [30]. In the case of tourists who use smartphones, they can accept or reduce risk if they decide to maintain or cancel certain features of their devices-which, for example, deny access to their location-while uncertainty may appear when mobile phones receive significant volumes of information that users are not able to process or when they receive unexpected commercial messages from other people or organisations.

In this article, perceived risk is defined as the subjective assessment that a user makes of adverse consequences and the probability that these consequences may occur with the purchase or use of a product [31]. If the risk perceived derives from the subjective assessment that each individual makes based on their knowledge of a given phenomenon and the calculation of the probability that an event with negative consequences takes place, the real risk may actually be lower than the individual's 
perceived risk [32]. Risk, therefore, can be a variable that influences individual's decision-making, but it is not clear if it affects this process more or less than other variables or the extent to which it influences users' decision-making.

Different tourists perceive risk differently [33]. This differing perception has been explained by socio-demographic and risk acceptance factors [34-36], cultural factors [37], psychosocial factors [38,39], motivational factors [40] and organisational factors [41]. In the case of the risk associated with the use of mobile phones in tourism, other factors should be considered in addition to the previously considered factors, such as the context in which the tourism activity is developed and how it differs from daily life [42]. Knowledge of and familiarity with the destination, trust in the service provider, and expertise in technology and travel [8].

Risk is a phenomenon that can be categorised. Thus, there are several types of perceived risk with particular characteristics that can obey different factors. In this sense, it is important to ask if different perceived risks related to the use of mobile phones have different effects on tourists' behaviour. Gretzel [9] identifies various types of risk associated with tourists' use of mobile phones. Capturing tourists' personal data and location—made possible by mobile devices—can threaten users' privacy [43], which sometimes poses an unconscious risk and raises ethical problems [44]. Privacy risk refers to the intrusion, collection and storage of tourists' personal data and their unauthorised use by others [45].

However, there is also a risk of eliminating or diminishing the elements of spontaneity and exploration in the tourist experience if the use of mobile phones generates dependence. The reduction of the uncertainty driven by the use of technology may contradict the search for risk and exploration that is an implicit part of the tourist experience [10]. The ability to choose for oneself is another component of the tourist experience that can be affected, if the user preference-based decisions enabled by technology are taken into account [46]. Thus, the reduction of uncertainty and inspiration caused by technology can affect the tourist experience, making it less exciting [9].

In fact, the perception of risk is considered to be a predictor of the intention to use the devices and technological applications that generate threats [8]. In this sense, there are several empirical studies that show the existence of a relationship between perceived risk and users' attitude towards the use of technology, which affirm that the concern for privacy is related to the utility that users associate with the technological applications used [47-49]. Thus, a positive assessment of the perceived usefulness of the devices or applications reduces the perceived risk of the use of mobile phones.

Technology use in the context of electronic service adoption has been explained using technology acceptance models (TAM), which incorporate risk in their analysis [50]. These theories are based on the proposition that tourists perceive risk prior to their purchase evaluation [51]. Risk perception among tourists has been analysed as a multidimensional phenomenon, given that consumers perceive several kinds of risk when shopping for products and services through technology [52]. Various facets of risk have been measured as drivers of consumer behaviour; however, only two risk types will be used for the purpose of our research: privacy risk and dependence on technology (over-dependence risk). Privacy risk refers to "the potential loss of control over personal information, such us when information about a traveller is used without his or her knowledge or permission" [53]. Tourists' dependence on technology is a psychological risk type in the sense that an intensive use of technology can have negative effects on the tourist experience and generate frustration in tourists. According to Gretzel [10], dependence on technology can even make the travel experience boring, since tourists can anticipate and make their planning process more effective, which reduces the level of human decision-making. Indeed, the use of digital technology for tourism purposes (what Gretzel calls "the digital gaze") makes the tourist experience more superficial, since tourists easily disconnect from their surroundings, leaving real life behind [10].

In our study, dependence is seen a valid measure of the mediated relationship existing between technology and visiting tourists. In other words, dependence will be used to measure the proximity that users/tourists have with technology while they are at a destination on holiday. Both types of 
risk have been selected in order to compare the combined influence of two opposite facets of risk on tourists' perception of the usefulness of mobile devices. Privacy risk is an a priori dissuasive element when it comes to the use of mobile devices, while dependence can be considered a trigger for the use of mobile devices. Our research places these two risk dimensions in relation to different variables of acceptance of the use of technology in order to examine how they influence the perception of the value of present, hedonic, and future use. Finally, we will also analyse how both facets of risk affect satisfaction in the tourist experience through the use of mobile phones.

Based on all of the aforementioned elements, it is clear that a relationship exists between tourists' perceived risk and their use of mobile phones. Thus, we assume that tourists' perceived risk of smartphone usage varies according to their personal characteristics. In addition, we believe that the perceived privacy and dependence risks modify the perceived usefulness of mobile phones among tourists.

Four hypotheses are derived from these assumptions:

H1. Tourists' perceived risk of the use of smartphones varies according to the personal characteristics of each individual.

H2. Tourists' perceived risks of mobile devices have opposing effects on their usefulness perception when these devices are used for tourism purposes. Thus, high levels of perceived privacy risk will reduce the perceived usefulness of smartphones, whereas high levels of dependence risk will increase the perceived usefulness of smartphones.

H2.1. Similarly, a high level of perceived privacy risk will decrease the perceived hedonic value of smartphones, whereas high levels of perceived dependence risk will increase the perceived hedonic value of smartphones.

H2.2. Finally, a high level of perceived privacy risk will decrease satisfaction in the tourist experience involving the use of smartphones, whereas a high level of perceived dependence risk will increase satisfaction.

\subsection{The Context of Beach Holiday Tourism in Catalonia}

The study was carried out through a survey developed simultaneously in two of the largest mass-tourism destinations on the Catalan coast: Sitges and Calella. These destinations provide an accurate representation of the diversity of tourist profiles interested in beach holidays. In this sense, the contributions that have been obtained can be easily transferred to other similar Catalan destinations and other territorial contexts. Both destinations are located in Catalonia, the Spanish autonomous community that receives the most international tourists. According to the Spanish National Statistics Institute, Catalonia received 17,032,814 tourists in 2016 [54], making it one of the most significant tourism regions in Europe. Sitges and Calella are located in the province of Barcelona, which has as its central axis one of the urban centres that has experienced the most spectacular growth in the number of international tourists in recent years: Barcelona. This city has positioned itself among Europe's most visited cities [55].

Combining the analyses of the tourists in Sitges and Calella allows us to place our overall analysis in the context of the variety of beach holiday destinations that exist in Catalonia. Both destinations present different elements-despite their similarities—while at the same time being representative in general of this type of destination. Due to its characteristics, Sitges has been defined as having a creative city model that currently is positioning itself as an intelligent and sustainable destination ([56], p. 58). It has a population of about 28,000 inhabitants and a hotel offering of 5000 places, plus 2000 pitches at campsites. It presents itself as an urban beach holiday destination that is complemented by an internationally competitive proposal in the area of congresses and conventions, culture, nautical tourism, wine tourism, nature, and the LGBT world. In the case of Calella, this destination represents a tourism model in which, to date, seasonality and very little specialisation have played a clear role in the schemes of what is called "mass tourism" [57]. Calella has 18,000 inhabitants, 11,000 hotel places and more than 2000 pitches at campsites. These figures show a higher index of economic specialisation 
in tourism than Sitges. In this context, there are new types of tourism offers that will be developed in order to respond to new trends in the sector. For instance, proposals exist to enable the evolution from mass tourism to quality tourism.

Both Sitges and Calella are destinations that have started to debate their conversion into smart tourism destinations, although these debates are still in the fledgling stage. Calella is currently managing a smart tourism destination plan that builds upon what this destination has to offer in order to differentiate itself and gain competitiveness based on the application of technology. Thus, the contributions this research makes to knowledge of tourists in relation to the use of smartphones in this particular destination are of special interest and can provide empirical elements that support the design of development strategies based on technologies for mobile devices.

\section{Materials and Methods}

The research carried out on the two Catalonian destinations, Calella and Sitges, involved delivering a survey to 532 tourists in the summer of 2016. All survey statements were addressed to domestic and international tourists visiting the destination during their summer holiday. The survey focused on tourists' perception of the risks and usefulness of mobile devices while visiting a tourism destination. The aim of the questionnaire was to gather information about respondents' mobile device usage behaviour and their perceptions of the risks of using them.

A structured questionnaire was developed, which included 22 questions about privacy risk perception, dependence on mobile devices while visiting a tourist destination as well as the perceived utility value, hedonic value and the intention of future use of mobile devices. All issues were measured on a 5-point Likert scale, where 1 corresponded with "completely disagree" and 5 with "completely agree". The survey also posed 10 questions regarding different socio-demographic aspects and several questions about the tourists' trip, technological skills, travel experience and previous knowledge about the destination. The survey instrument was conducted during the summer tourist season (August-September 2016) by a team specialised in tourism and market research surveys, and it was randomly administered to tourists visiting the main attractions or walking through downtown public spaces. The tourist attractions were chosen on the basis of the number of tourists visiting particular places. Only tourists over the age of 16 were surveyed, as tourists younger than 16 were not considered mature enough to judge the degree of risk perception of using mobile devices. Only holidaymakers were sought for the study.

The questions regarding perceived risk were selected from previous literature. According to Beinat [58], privacy risk issues involve the ability to collect, store, use and disclose users' locations. Other literature identifies various aspects that characterise privacy risk (improper access to and the collection and unauthorised secondary use of personal information), which were taken into account when designing the issues surveyed in this study [8,45,53,59-61]. Subsequently, several questions were included in order to obtain information on privacy risk perception: "It bothers me that when I use mobile devices I can be observed by other people or they can know my exact position"; "It upsets me if my personal data is used to offer me customised services and products"; "I like to receive messages about personalised services and product offers on my mobile device when I'm on holiday"; and "I like to post personal comments and photographs on social media, despite the fact that someone may recognise me or figure out where I am".

In this study, dependence on mobile devices refers to a pattern of tourist behaviour that favours the use of this technology when tourists are visiting a destination based on a preferred use of mobile devices over other traditional options (maps, book guides, etc.) and with a high intensity of use. Some authors point out that the use of smartphones is associated with a high emotional relationship, which positively affects the tourist experience [21], whereas other authors state that a high dependence on smartphones is related to a low level of perceived satisfaction with the experience [10].

In our research, dependence risk was measured based on three criteria. First, we examined intensity of use ("When I'm on holidays I switch off my mobile devices in order to enjoy my stay 
and rest" and "I like to let myself get lost in a destination when I am on holiday (without having to look at my mobile devices)"). Second, we examined the user's decision, whether it was an intrinsic decision ("I prefer to prepare holidays and travel itineraries on my own (without technology)") or an extrinsic decision ("It would bother me if I had to use a mobile device when visiting a monument or tourist attraction in order to best interpret or understand the content and/or information offered"). Finally, a substitutive or preference of use criteria for mobile devices compared to other possibilities was evaluated with the question, "If I need guidance, I prefer to use my mobile device rather than figure it out myself".

The impact of perceived risk on tourists' experience was analysed through a construct that includes two elements: satisfaction on tourist experience and fun, expressed as the hedonic value derived from the use of mobile devices. Satisfaction is generally discussed as the overall tourism experience. It is a context-dependent process consisting of a multi-model, multi-modal blend of motivations, cognitions, emotions and meanings embedded in sociocultural settings that transforms during consumer-product interactions [62]. In our research, technology (mobile devices) is understood as an element that shapes the experience as tourists uses it to enhance their visit experience, to extend their sensory reach [10] and increases possibilities for social connections and for feelings of co-presence [19].

From a consumer point of view, hedonic value refers to experiences that are positive, fun and intrinsically enjoyable [63]. Tourism is an extremely hedonic experience and, for most tourists, fun is an experienced utility and the essence of a consumption episode $[64,65]$. Tourist experiences are hedonic in nature and mobile devices can act as a utility for pleasure derived from their use in a tourism context. We believe that mobile devices are presumably better able to engage with the tourist experience, especially if the use of mobile devices is perceived as an enjoyable task or if they are considered to be a tool that helps to create a more enjoyable tourist experience. Thus, the survey included three items as a measure for hedonic value associated with the use of mobile devices: "Using mobile devices when visiting as a tourist is fun", "The use of mobile devices makes my trip more interesting, fun and enjoyable" and "The application of technology (e.g., augmented reality) in mobile devices is an incentive to enjoy tourism sites". Finally, the variables used to measure the perceived usefulness and perceived intention of future use of mobile devices were selected from items generally employed to describe the acceptance of use of mobile technology in a tourism context [66]. This involved the question: "I will use mobile devices again on my next holiday".

The results of the survey were reached by running a cluster analysis to determine four tourist typologies. This was possible using information on tourists' socio-demographic, technology usage and perceived risk variables. For the formation of these clusters, 391 survey cases were determined to be valid and the resulting averages of 22 variables were analysed for each cluster. Thirteen of these variables allowed results to be attained regarding perceived utility value, perceived hedonic value, and future use.

Cluster analysis is a technique used in a wide range of tourism research relying on different approaches $[67,68]$. The objective of cluster analysis is to isolate different groups in a sample by studying their common characteristics. It is understood to be a more accurate form of analysis than simply analysing the means to create significant groups. On this occasion, a non-hierarchical method was selected (as in the 2004 work of Aguiló-Pérez and Roselló-Nadal [67]) regarding the number of respondents and the reduction of the effect of rare cases [69]. In addition, means techniques were also applied in the form of an ANOVA test of the variables on the Likert scale as a technique for validating the variables in the clusters.

Finally, frequency distribution of the variables was conducted to identify the respondents' profiles of origin (Spanish tourists and international tourists) and compare means and standard deviations for each risk variable. A one-way ANOVA test was carried out to compare the two tourist profiles and to identify if they had different perceptions about risk when using mobile devices. 


\section{Results}

After some iterations, four clearly defined groups (Table 1) were obtained by taking into account socio-demographic variables such as sex and age as well as other variables related to the number of trips to the destination, the travel experience, tourists' use of technology and their experience of its use. These variables were compiled together with others involving the perception of the risk to privacy and variables involving dependence on the use of technology before the trip and as a resource for guidance at the destination. The criteria within the iterations required at least two experience variables involving the use of mobile devices, two privacy risk perception variables and two dependence risk perception variables. Table 2 shows the disparity between the groups, in which the most distant groups are Cluster 2 and Cluster 4 and the closest groups are Cluster 1 and Cluster 4.

Table 1. Centres of the final clusters.

\begin{tabular}{|c|c|c|c|c|}
\hline & \multicolumn{4}{|c|}{ Clusters } \\
\hline & 1 & 2 & 3 & 4 \\
\hline Woman/Man & $\mathrm{W}$ & $\mathrm{W}$ & $\mathrm{W}$ & $\mathrm{M}$ \\
\hline $\begin{array}{l}\text { How many times have you visited } \\
\text { the destination? }\end{array}$ & One time & $\begin{array}{l}\text { More than } \\
\text { five times }\end{array}$ & Four or five times & One time \\
\hline $\begin{array}{l}\text { For what purpose do you mainly use } \\
\text { mobile devices? }\end{array}$ & $\begin{array}{l}\text { To have fun and for } \\
\text { entertainment }\end{array}$ & $\begin{array}{l}\text { To have fun and for } \\
\text { entertainment }\end{array}$ & $\begin{array}{l}\text { To find information, } \\
\text { have fun and for } \\
\text { entertainment }\end{array}$ & $\begin{array}{l}\text { To have fun and for } \\
\text { entertainment }\end{array}$ \\
\hline $\begin{array}{l}\text { I'm aware of what's new in apps for } \\
\text { mobile devices. * }\end{array}$ & 3 & 3 & 4 & 4 \\
\hline $\begin{array}{l}\text { It bothers me that when I use mobile } \\
\text { devices I can be observed by other } \\
\text { people or they can know my } \\
\text { exact position. * }\end{array}$ & 4 & 4 & 4 & 3 \\
\hline $\begin{array}{l}\text { It upsets me if my personal data is used } \\
\text { to offer me customised services } \\
\text { and products. * }\end{array}$ & 4 & 3 & 4 & 3 \\
\hline $\begin{array}{l}\text { I prefer to prepare holidays and travel } \\
\text { itineraries on my own } \\
\text { (without technology). }\end{array}$ & 2 & 3 & 3 & 3 \\
\hline $\begin{array}{c}\text { If I need guidance, I prefer to use my } \\
\text { mobile device rather than figure it } \\
\text { out myself. }\end{array}$ & 3 & 3 & 4 & 4 \\
\hline
\end{tabular}

Table 2. Inter-cluster variability.

\begin{tabular}{ccccc}
\hline Cluster & $\mathbf{1}$ & $\mathbf{2}$ & $\mathbf{3}$ & $\mathbf{4}$ \\
\hline 1 & - & - & - & - \\
2 & 4.083 & - & - & - \\
3 & 3.610 & 2.551 & - & - \\
4 & 2.191 & 4.352 & 3.335 & - \\
\hline
\end{tabular}

The results of Table 1 (Clusters) created the following groups:

Cluster 1 (117 cases, 29.9\% of the sample): Low Technology, High Awareness, Young Occasional Travellers. This group represents a young population (millennials between 25 and 34 years of age) in which women prevail. Members of this group are travelling for the first time to the destination and have an intermediate profile of annual trips. They use mobile devices predominantly for entertainment 
and do not consider themselves highly skilled in technology. However, they are concerned about the control and use of their data and they do not use technology intensively during their stay at the destination. Instead, they choose to use their mobile devices in the holiday planning phase.

Cluster 2 (46 cases, 11.7\% of the sample): Low Use, Low Awareness, Senior Intensive Travellers. This group comprises a majority of women of a more mature age (between 45 and 54 years of age) but having made numerous visits to the destination and a high frequency of travel. Their main use of mobile devices is for entertainment, and they express a greater global concern than the previous group regarding the privacy risks in regard to the control of their movements and indifference regarding the possibility of personalised communication. There seems to be no dependence on technology among this group, as members maintain neutral positions about the use of technology.

Cluster 3 (91 cases, 23.3\% of the sample): High Awareness, Generation X Intensive Travellers. This group is comprised primarily of tourists from generation $X$ (between 35 and 44 years of age) who are mostly women and see themselves as knowledgeable about technology and its applications, which they use to inform and entertain themselves. They are travellers who are familiar with the destination from other visits and travel frequently during the year. This group is aware of mobile device privacy issues and the inconvenience that this can bring. However, they seem to exhibit a certain intensity in the level of use of devices at a destination.

Cluster 4 (137 cases, 35\% of the sample): Techy, Unconcerned Young Male, Intensive Travellers. The last group has its own characteristics. This group is primarily made up of young men (millennials between 25 and 34 years of age) visiting the destination for the first time but who travel approximately four times a year. As for mobile devices, they use them to get information and entertain themselves, they are technology-savvy but do not express perception of risk, and they use mobile devices at destinations more intensively than other groups.

To continue with the analysis, Table 3 shows the average of each variable by clusters; scores over four are highlighted. The first nine variables are related to the use and perception of technology. Among these questions, we can find questions that focus on the experience of using mobile devices, perception of privacy risks, and questions about the perception of risk and over-dependence on technology. The last 13 questions are related to the perceived utility value of the devices, their perceived hedonic value, and tourists' intention to continue using them in the future $[66,70,71]$. The following conclusions can be made by analysing the averages by variables and clusters.

In Cluster 1, the risk perceived by its members-especially in terms of privacy-is associated with a vision of the hedonic and utilitarian value of mobile devices. Thus, it is relatively low compared to the rest of the clusters. In addition, the intention to use mobile devices in the future is the lowest of all clusters. On the other hand, the responses of members of this cluster emphasise a lower utilitarian than hedonic value.

Looking at the data (Table 3), it can be affirmed that this cluster has intermediate positions regarding the updated use of technology and the recognition of its capabilities (Variables 1,2 and 3). However, the members of this cluster are the most upset about the possible privacy risks: they do not like to receive personalised offers (Variable 6) and they are bothered by the possibility of being geolocated (Variable 4). However, they are also the most reluctant to prepare a trip without technology (Variable 7). On the other hand, together with Cluster 2, Cluster 1 maintains an intermediate position regarding the perception of enrichment of the tourist experience thanks to mobile devices (Variables 11 and 13) and seems to value the use of technology on social media more positively than members from Cluster 2 (Variables 16 and 17). Finally, the general opinion of future use is positive in this cluster, but it is still the lowest of all the clusters (Variables 21 and 22).

In Cluster 2, the low value of risk perceived is associated with the perception of the hedonic value and utility of mobile devices. In this case, it is the lowest among all the groups. In other words, not perceiving risk in the use of mobile devices does not appear to be associated with a positive evaluation of them. Unlike the previous cluster, the utility value of mobile devices is ranked above the hedonic 
value. Finally, the members' intention to use mobile devices in the future for holiday purposes is also slightly higher than in the previous cluster.

The data show that this cluster can be considered the most insecure and least up-to-date regarding the use of mobile devices (Variables 1,2 and 3). Along with the members of Cluster 1, the members of Cluster 2 are the most disturbed by personalised offers (Variable 6 ) and by the possibility of geolocation tracking (Variable 4). At the same time, they are also the tourists who are the least predisposed to using mobile devices for certain tourism utilities, including for general guidance or at the monuments or tourist attractions themselves (Variables 8 and 10). They also maintain the lowest score in other aspects of hedonic use, such as that travel is fun with mobile devices (Variable 14) or that using a feature such as augmented reality is an incentive to enjoy the experience (Variable 15). They also stand out for their indifferent position towards social media in tourism (Variables 18 and 19), but have a positive perspective regarding future use that is superior to that of Cluster 1 (Variables 21 and 22).

Table 3. Mean responses of clusters to the 22 statements.

\begin{tabular}{|c|c|c|c|c|}
\hline & C1 & $\mathrm{C} 2$ & $\mathrm{C} 3$ & $\mathrm{C} 4$ \\
\hline 1. I'm aware of what's new in apps for mobile devices. * & 3.21 & 2.98 & 4.24 & 4.03 \\
\hline 2. Compared to others, I have no problems in running technological devices. * & 3.34 & 2.85 & 4.09 & 4.18 \\
\hline 3. I'm aware of new developments in technology in general. * & 3.60 & 3.28 & 4.31 & 4.31 \\
\hline $\begin{array}{l}\text { 4. It bothers me that when I use mobile devices I can be observed by other people or they } \\
\text { can know my exact position. * }\end{array}$ & 3.97 & 3.87 & 3.74 & 3.19 \\
\hline 5. It upsets me if my personal data is used to offer me customised services and products. * & 4.05 & 3.39 & 4.02 & 2.89 \\
\hline $\begin{array}{l}\text { 6. I like to receive messages about personalised services and product offers on my mobile } \\
\text { device when I'm on holiday. * }\end{array}$ & 2.35 & 2.46 & 2.84 & 2.60 \\
\hline 7. I prefer to prepare holidays and travel itineraries on my own (without technology). * & 2.26 & 2.76 & 3.03 & 3.25 \\
\hline 8. If I need guidance, I prefer to use my mobile device rather than figure it out myself. * & 3.44 & 2.74 & 3.76 & 3.82 \\
\hline $\begin{array}{l}\text { 9. I like to let myself get lost in a destination when I'm on holiday (without having to look } \\
\text { at my mobile devices). }\end{array}$ & 3.15 & 3.17 & 3.35 & 3.46 \\
\hline $\begin{array}{l}\text { 10. It would bother me if I had to use a mobile device when visiting a monument or } \\
\text { tourist attraction in order to best interpret or understand the content and/or } \\
\text { information offered. * }\end{array}$ & 3.72 & 3.80 & 3.66 & 3.27 \\
\hline 11. The use of mobile devices makes my trip more interesting, fun and enjoyable. ${ }^{*}$ & 3.34 & 3.22 & 3.78 & 3.77 \\
\hline 12. I like to use mobile devices when I travel. * & 3.72 & 3.59 & 4.04 & 4.03 \\
\hline $\begin{array}{l}\text { 13. I believe that the use of mobile devices when visiting a destination enriches my } \\
\text { tourist experience. * }\end{array}$ & 3.35 & 3.30 & 3.92 & 3.76 \\
\hline 14. Using mobile devices when visiting as a tourist is fun. * & 3.22 & 3.12 & 3.59 & 3.72 \\
\hline $\begin{array}{l}\text { 15. The application of technology (e.g., augmented reality) in mobile devices is an } \\
\text { incentive to enjoy tourism sites. * }\end{array}$ & 3.16 & 3.00 & 3.53 & 3.46 \\
\hline 16. I like to find tips on social media networks to decide where to go on holiday. ${ }^{*}$ & 3.47 & 3.17 & 3.68 & 3.70 \\
\hline $\begin{array}{l}\text { 17. I like to search for tips on social media networks to decide what to do on holiday at } \\
\text { a destination. * }\end{array}$ & 3.56 & 3.15 & 3.66 & 3.71 \\
\hline $\begin{array}{l}\text { 18. When I want information or I need to know something about a destination, I prefer to } \\
\text { ask people on the street than use mobile devices. }\end{array}$ & 2.91 & 3.20 & 2.96 & 3.07 \\
\hline $\begin{array}{l}\text { 19. I like to use mobile devices and technology to better interpret what I'm seeing when I } \\
\text { go on a tour. }\end{array}$ & 3.22 & 3.22 & 3.74 & 3.54 \\
\hline $\begin{array}{l}\text { 20. When I'm on holiday and I'm looking for information, I prefer mobile devices over } \\
\text { tourist information centres on the street. }{ }^{*}\end{array}$ & 3.14 & 3.13 & 3.52 & 3.45 \\
\hline 21. I will use mobile devices again on my next holiday. ** & 4.10 & 4.26 & 4.31 & 4.32 \\
\hline 22. In the future, mobile devices will be of use to me when going on holiday. * & 4.09 & 4.09 & 4.35 & 4.31 \\
\hline
\end{tabular}

$$
{ }^{*} \text { ANOVA under } 0.05 ;{ }^{* *} \text { ANOVA }=0.101 ;{ }^{* * *} \text { ANOVA }=0.4 \text {. }
$$

In Cluster 3, the members indicate that they have a high level of perceived risk both in terms of privacy issues and mobile device dependence. In this case, both the members' perception of the hedonic value (especially regarding the contribution made to their tourist experience) and the utility value (particularly in the search for information and interpretation of the tourist visit) are high. 
In addition, their evaluation of the future use of mobile devices for holidays is quite high, above that of the previous two groups.

Looking closely at the averages, we can see that the members of Cluster 3 are aware of updates (Variables 1 and 3) and have no problems using their devices (Variable 2). Together with Cluster 1, they express the greatest amount of dissatisfaction when receiving customised services or products related to their data (Variable 5), but they also regard most positively the use of devices on trips (Variables 11, 12 and 13). After Cluster 4, Cluster 3 is made up of members who best accept the use of social media while travelling (Variables 16 and 17). In addition, this cluster is the one that holds in the highest regard the utility of mobile devices for interpreting what they see at the destination and as a source of information, even over a tourist information centre (Variables 19 and 20). Finally, they stand out for their intention of future use (Variables 21 and 22).

Finally, Cluster 4's members express a low level of perceived risk of mobile device usage, which can be associated with their high valuation of the hedonic and utilitarian value of these devices. Tourists belonging to this cluster particularly value the entertainment dimension provided by mobile devices and the use of social media during the tourist experience. Their evaluation of future use of mobile devices for tourism is also quite high.

As can be seen in Table 3, Cluster 4's members are the most confident when using mobile devices (Variable 2), and they also rank highly with regard to application and technology updates, along with members from Cluster 3 (Variables 1 and 3). However, the members of Cluster 4 are the least bothered by the possibility of their data being used to receive personalised products and services (Variable 5). Their positive attitude towards mobile devices can also be observed in their preference for using mobile devices to guide themselves (Variable 8), and, together with Cluster 3, they emphasise that they like to use their mobile devices when they travel (Variable 12). This cluster has a higher score than the others regarding the opinion that travel is fun with mobile devices (Variable 14) and about the use of social media (Variables 16 and 17). Finally, members also show a greater predisposition to use these devices on their future trips, together with Cluster 3 (Variables 21 and 22).

Table 4 analyses the distribution of tourists among the clusters in each destination. As can be seen, Sitges has a more homogeneous distribution due to the more diversified profile of its tourists.

Table 4. Distribution of Clusters per destination.

\begin{tabular}{|c|c|c|c|c|c|}
\hline & \multicolumn{4}{|c|}{ Cluster } & \multirow{2}{*}{ Total } \\
\hline & 1 & 2 & 3 & 4 & \\
\hline Sitges & $52(23.7 \%)$ & $35(16.0 \%)$ & $70(32.0 \%)$ & $62(28.3 \%)$ & $219(100.0 \%)$ \\
\hline Calella & $65(37.8 \%)$ & $11(6.4 \%)$ & $21(12.2 \%)$ & 75 (43.6\%) & $172(100.0 \%)$ \\
\hline Total & 117 (29.9\%) & $46(11.8 \%)$ & $91(23.3 \%)$ & $137(35.0 \%)$ & $391(100.0 \%)$ \\
\hline
\end{tabular}

A further step in the research involved assessing the relationship between tourists' perceived risk and the use of mobile devices through regression analysis. For this purpose, four models were evaluated. The first model assessed the influence of nine independent variables regarding tourists' perceived usefulness of mobile devices. Variables related to risk perception were divided into two groups: privacy risk perception and dependence. Privacy risk perception was measured through two different questions related to personal location concerns ("It bothers me that when I use mobile devices I can be observed by other people or they can know my exact position"), and the use of personal data ("It upsets me if my personal data is used to offer me customised services and products").

Dependence was measured through two questions related to the degree of indispensable need, use intensity and closeness between tourists and their mobile devices when visiting a destination: "When I want information or I need to know something about a destination, I prefer to ask people on the street rather than use mobile devices" and "I prefer to prepare holidays and travel itineraries on my own (without technology)". The destination knowledge variable was measured by the question, "How many times have you visited this destination?". Travel experience was measured by the question, 
"How many times do you travel in a year?". Finally, the technology skills variable was measured by the question "I consider myself to be skilled in the use of technology". The dependent variable (perceived usefulness of mobile devices) was measured by the question, "I consider mobile devices to be useful for tourism and travel purposes".

The second model assessed the influence of the same independent variables on a second dependent variable, namely the improvement of tourist experience when using mobile devices. The dependent variable (tourist experience) was measured by the question, "I believe that the use of mobile devices when visiting a destination enriches my tourist experience". The third model assessed the influence of the same independent variables on a third dependent variable: the hedonic value of mobile devices. This dependent variable (hedonic value) was measured by the question, "The use of mobile devices makes my trip more interesting, fun and enjoyable". Finally, a fourth model assessed the influence of the same independent variables on a new dependent variable: tourists' intention to use mobile devices in the future. In this case, the dependent variable (future use intention) was measured with the question, "I will use mobile devices again on my next holiday".

The results of Model 1 indicate that the variables for perceived privacy risk, dependence and age are statistically significant predictors $(\alpha \leq 0.005)$ of tourists' perceived usefulness of mobile devices (see Table 5). $R^{2}$ is 0.19 , which explains $19.6 \%$ of the variance in tourists' perception of the usefulness of mobile devices. Inspection of beta-coefficients shows that age is the most influential explanatory variable at 0.216 , followed by dependence (intensity of use of mobile devices) at -0.200 , and dependence (substitutive use of mobile devices) and risk privacy (geolocation concerns), with a value of 0.177 .

Table 5. Regression results. Model 1: The perceived usefulness of mobile devices.

\begin{tabular}{lccccc}
\hline \multicolumn{1}{c}{ Independent Variables } & $\boldsymbol{\beta}$ & $\boldsymbol{t}$-Value & Sig. $\boldsymbol{t}$ & $\mathbf{R}^{\mathbf{2}}$ & Sig $\boldsymbol{F}$ \\
\hline Constant & & 5.041 & 0.001 & 19.6 & 0 \\
Privacy risk (inappropriate use of personal data) & -0.092 & -1.817 & 0.070 & & \\
Privacy risk (geolocation concerns) & 0.177 & 3.339 & 0.001 & & \\
Dependence (substitutive use of mobile devices) & -0.200 & -3.974 & 0.001 & & \\
Dependence (intensity of use of mobile devices) & 0.190 & 3.809 & 0.000 & & \\
Gender & 0.059 & 1.185 & 0.237 & & \\
Age & 0.216 & 4.111 & 0.000 & & \\
Destination knowledge & -0.002 & 0.000 & 0.971 & \\
Travel experience & 0.025 & 0.000 & 0.604 & \\
Technology skills & 0.106 & 1.918 & 0.056 & & \\
\hline
\end{tabular}

Note: Dependent variable: Mobile devices perceived usefulness.

The results of Model 2 (Table 6) indicate that the variables for perceived privacy risk (inappropriate use of personal data), dependence, technological skills and age are statistically significant predictors $(\alpha \leq 0.005)$ of an increase in satisfaction of a tourist experience involving the use of mobile devices. In this case, $R^{2}$ is 0.29 , which means that $29 \%$ of the variance in tourists' perception of mobile devices increases their tourist experience. Inspection of beta coefficients shows that dependence is the most influential explanatory variable, at 0.319 , followed by age, at 0.217 , technological skills, at 0.187 , and risk privacy, at 0.145 .

The results of Model 3 (Table 7) indicate that the variables for dependence and age are statistically significant predictors $(\alpha \leq 0.005)$ of the tourists' perceived hedonic value of mobile devices. In this case, $R^{2}$ is 0.23 , which explains $23 \%$ of the variance in tourists' perception of mobile devices increasing their tourist experience. Inspection of beta coefficients shows that dependence (substitution use of mobile devices) is the most influential explanatory variable at 0.248 , followed by age, at 0.192 .

The results of Model 4 (Table 8) indicate that the variables for dependence (substitution use of mobile devices), technological skills and age are statistically significant predictors $(\alpha \leq 0.005)$ of the tourists' future intention to use mobile devices during their holidays. $\mathrm{R}^{2}$ is 0.19 , which explains $19 \%$ 
of the variance in tourists' perception of intention of future use of mobile devices. An inspection of beta-coefficients shows that age is the most influential explanatory variable, at 0.233 , followed by technological skills, at 0.203 , and dependence, at 0.156 .

Table 6. Regression results. Model 2: Perceived tourist experience satisfaction with mobile device usage.

\begin{tabular}{lccccc}
\hline \multicolumn{1}{c}{ Independent Variables } & $\boldsymbol{\beta}$ & $\boldsymbol{t}$-Value & Sig. $\boldsymbol{t}$ & $\mathbf{R}^{\mathbf{2}}$ & Sig $\boldsymbol{F}$ \\
\hline Constant & & 3.203 & 0.001 & 29.6 & 0.000 \\
Privacy risk (inappropriate use of personal data) & 0.145 & 3.057 & 0.002 & & \\
Privacy risk (geolocation concerns) & 0.060 & 1.200 & 0.231 & & \\
Dependence (substitutive use of mobile devices) & -0.033 & -0.695 & 0.488 & & \\
Dependence (intensity of use of mobile devices) & 0.319 & 6.823 & 0.000 & & \\
Gender & -0.099 & -2.148 & 0.033 & & \\
Age & 0.217 & 4.409 & 0.000 & & \\
Destination knowledge & 0.009 & 0.200 & 0.842 & & \\
Travel experience & -0.005 & -0.105 & 0.917 & \\
Technology skills & 0.187 & 3.627 & 0.000 & & \\
\hline
\end{tabular}

Note: Dependent variable: Tourist experience satisfaction.

Table 7. Regression results. Model 3: Perceived hedonic value of mobile devices.

\begin{tabular}{lccccc}
\hline \multicolumn{1}{c}{ Independent Variables } & $\boldsymbol{\beta}$ & $\boldsymbol{t}$-Value & Sig. $\boldsymbol{t}$ & $\mathbf{R}^{\mathbf{2}}$ & Sig $\boldsymbol{F}$ \\
\hline Constant & & 2.943 & 0.003 & 26.6 & 0.000 \\
Privacy risk (inappropriate use of personal data) & 0.115 & 2.381 & 0.018 & & \\
Privacy risk (geolocation concern) & 0.127 & 2.505 & 0.013 & & \\
Dependence (substitutive use of mobile devices) & -0.018 & -0.377 & 0.706 & & \\
Dependence (intensity of use of mobile devices) & 0.248 & 5.202 & 0.000 & & \\
Gender & -0.034 & -0.722 & 0.471 & & \\
Age & -0.192 & 3.904 & 0.000 & & \\
Destination knowledge & -0.048 & -0.986 & 0.325 & & \\
Travel experience & 0.006 & 0.124 & 0.901 & \\
Technology skills & 0.133 & 2.511 & 0.012 & & \\
\hline
\end{tabular}

Note: Dependent variable: Hedonic value.

Table 8. Regression results. Model 4: Future intention to use mobile devices.

\begin{tabular}{lccccc}
\hline \multicolumn{1}{c}{ Independent Variables } & $\boldsymbol{\beta}$ & $\boldsymbol{t}$-Value & Sig. $\boldsymbol{t}$ & $\mathbf{R}^{\mathbf{2}}$ & Sig $\boldsymbol{F}$ \\
\hline Constant & & 6.847 & 0.000 & 19.7 & 0.000 \\
Privacy risk (inappropriate use of personal data) & -0.039 & -0.769 & 0.442 & & \\
Privacy risk (geolocation concerns) & 0.137 & 2.584 & 0.010 & & \\
Dependence (substitutive use of mobile devices) & -0.033 & -0.661 & 0.509 & & \\
Dependence (intensity of use of mobile devices) & 0.156 & 3.105 & 0.002 & & \\
Gender & -0.030 & -0.608 & 0.543 & & \\
Age & 0.233 & 4.439 & 0.000 & & \\
Destination knowledge & -0.034 & -0.672 & 0.502 & & \\
Travel experience & 0.042 & 0.875 & 0.382 & & \\
Technology skills & 0.203 & 3.657 & 0.000 & & \\
\hline
\end{tabular}

Note: Dependent variable: Future intention to use mobile devices.

Finally, a one-way ANOVA test was carried out to determine if there were significant differences in risk perception among domestic (Spanish, $n=154)$ and international $(n=257)$ tourists. The ANOVA test revealed that there were significant differences among tourists from different countries in 2 out of 8 measurement variables (see Table 9). Spanish tourists were less dependent on mobile devices and technology and more concerned about risk issues than international tourists. Spanish tourists were especially concerned about the risk of loss of privacy when using social media, whereas international 
tourists were more tolerant of this risk. Similarly, Spanish tourists were more opposed to the obligatory use of mobile devices when visiting a tourism site than international tourists. These differences suggest a different cultural approach to technology use and risk that would need further analysis in order to be confirmed.

Table 9. Differences in tourist risk perception across country of origin.

\begin{tabular}{|c|c|c|c|c|c|}
\hline Variable & $\begin{array}{c}\text { Spanish } \\
n=154\end{array}$ & $\begin{array}{l}\text { International } \\
\quad n=257\end{array}$ & $\begin{array}{l}\text { Mean (Total) } \\
\quad n=411\end{array}$ & $F$ & Sig. \\
\hline $\begin{array}{l}\text { Dependency } 1 \text { (I prefer to prepare holidays and } \\
\text { travel itineraries on my own (without technology)) }\end{array}$ & 2.93 & 2.90 & 2.85 & 1.101 & 0.295 \\
\hline $\begin{array}{l}\text { Dependency } 2 \text { (I like to let myself get lost in a } \\
\text { destination when I'm on holiday (without having to } \\
\text { look at my mobile devices)) }\end{array}$ & 3.30 & 3.33 & 3.22 & 0.085 & 0.770 \\
\hline $\begin{array}{l}\text { Dependency } 3 \text { (If I need guidance, I prefer to use my } \\
\text { mobile device rather than figure it out myself) }\end{array}$ & 3.41 & 3.63 & 3.55 & 4.520 & 0.034 \\
\hline $\begin{array}{l}\text { Privacy } 1 \text { (It bothers me that when I use mobile } \\
\text { devices I can be observed by other people or they } \\
\text { can know my exact position) }\end{array}$ & 3.72 & 3.55 & 3.62 & 2.065 & 0.152 \\
\hline $\begin{array}{l}\text { Privacy } 2 \text { (I like to receive messages about } \\
\text { personalised services and product offers on my } \\
\text { mobile device when I'm on holiday) }\end{array}$ & 2.49 & 2.61 & 2.56 & 0.091 & 0.343 \\
\hline $\begin{array}{l}\text { Privacy } 3 \text { (It upsets me if my personal data is used to } \\
\text { offer me customised services and products) }\end{array}$ & 3.75 & 3.41 & 3.54 & 7.350 & 0.007 \\
\hline $\begin{array}{l}\text { Dependency } 4 \text { (It would bother me if I had to use a } \\
\text { mobile device when visiting a monument or tourist } \\
\text { attraction in order to best interpret or understand } \\
\text { the content and/or information offered) }\end{array}$ & 3.90 & 3.35 & 3.56 & 22.99 & 0.000 \\
\hline $\begin{array}{l}\text { Privacy } 4 \text { (I like to post personal comments and } \\
\text { photographs on social media, despite the fact that } \\
\text { someone may recognise me or figure out where I am) }\end{array}$ & 3.02 & 3.49 & 3.31 & 13.077 & 0.000 \\
\hline
\end{tabular}

\section{Discussion}

Cluster analysis results indicate that there are four groups of tourists with different profiles of mobile device usage and perceptions regarding the risk of privacy and dependence on technology. It is worth mentioning the contrast between the tourists with a high degree of experience with technology, frequent use and little perception of risk and over-dependence and other tourists with other socio-demographic and technological profiles who perceive risks differently.

One of the objectives of this study was to analyse the existing differences in tourists' perception of the risk associated with the use of mobile devices. The results show that tourists perceive this type of risk very differently. Two of the four groups of tourists surveyed expressed a high degree of perceived risk, while the other two groups showed having a low perception of risk. Furthermore, behaviour regarding the perception of the two types of risk analysed was not completely homogeneous. The perception of risk linked to privacy was high in three of the four groups, while the perception of risk associated with dependence on mobile devices was lower in relation to the risk of privacy in three of the four groups.

The variables related to the tourist experience, technology expertise, preferential use given to mobile devices and previous knowledge of the destination behave much more erratically than the socio-demographic variables as they associate with tourists' perceived risk. In fact, all of them can be associated with both high and low perceived risk components, which suggests a weak link with perceived risk. On the other hand, the influence of socio-demographic factors on tourists' perception of risk when using mobile devices is more significant. Gender and age are two key factors that can be used to understand behaviour in relation to the tourists' perceived risk of mobile usage. Two of the three groups of tourists identified in which women predominated showed a high perception of risk, 
whereas the perception of risk was low only in the group in which men predominated. In addition, the average response to risk for each group of tourists indicates that the lowest perceived risk scores only appeared in the group in which men predominated.

There are also considerable differences in relation to perceived risk regarding age. Young people in the millennial generation demonstrated "canonical" behaviour in their perception of risk. Thus, individuals who expressed a high degree of perceived risk had a low valuation of the utility and hedonic value of mobile devices and vice versa. Older tourists, on the other hand, expressed unfavourable opinions towards the use of mobile devices, although they also demonstrated the lowest perception of risk of all the tourist groups surveyed. In addition, they also expressed a low valuation of the utilitarian and hedonic value of mobile devices. Finally, the members of the so-called generation $X$ presented a situation contrary to that of the previous group of seniors. In this case, they expressed a very high perception of risk, but also highly evaluated perceived utility and hedonic value.

Overall, three groups showed that their intention to use mobile devices in the future was very high, especially with regard to the group belonging to generation X. Thus, individuals in both of the seaside cities analysed perceived the same risk differently, as other studies have shown regarding the influence of tourists' perceived risk on their choice of destination [37]. In this sense, the differences detected among young millennials in their perception of the risk posed by mobile devices are better understood.

These differences in perception suggest that the different types of risk perceived by each individual may also be due to different reasons. In future research, it will be necessary to analyse which factors of the individuals' profiles can explain the differences between each type of risk perceived and if there is any relationship between the presence or absence of one type of risk and another. In this sense, exploring factors related to a passionate use of mobile devices and the perception of risk might be an enriching path to better understanding different tourist behaviours.

Regression analysis shows that age, risk to privacy, dependence and technology skills are all significant variables. Surprisingly, however, age acted in a way opposite to that hypothesised. Our results demonstrated that age is a factor that positively influences the perceived value of mobile devices. This can be interpreted in a twofold manner. First, our results support other researchers' statements about the use of smartphones in digital marketing, which claim that the existing gap is narrowing, as more consumers from all age groups embrace mobile marketing through increased smartphone penetration [72]. A second interpretation, complementary to the previous one, involves older generations' perceptions of the utility value of mobile devices. According to our study, these age groups feel that mobile devices and technology in general provide a useful, previously non-existent solution to problems in their daily life (and tourism activity). Unlike older generations, young people - and digital natives in particular-do not seem to expect as much from technology, because they do not see them as disruptive innovation but rather a natural, everyday tool. A future area of study could include in-depth analysis of the observed differences between tourist age groups in order to better understand the factors that explain the differences in their perceptions of technology and mobile devices.

Privacy risk was associated significantly with the perceived usefulness of mobile devices and satisfaction with the travel experience. Thus, tourists positively evaluated the usefulness of their mobile devices despite the perceived risk. Indeed, privacy risk in regard to geolocation was correlated with the utility value tourists gave to mobile devices. These results support other research stating that people are less concerned about their location being tracked as long as they find the service useful [49]. Finally, perceived privacy risk due to an inappropriate use of personal data by others was negatively correlated with tourists' satisfaction with the tourist experience. In this case, the results did not support the thesis that tourists tend to underestimate risk when using their mobile devices in a leisure and tourism context [10]. Dependence was positively correlated with the four regression models. Thus, dependence on mobile devices does correlate with a positive perception of these devices. Unlike privacy risk, dependence is also correlated positively with hedonic use and future intention to use mobile devices. This is consistent with the fact that tourists with a high dependence on mobile devices 
also have a highly positive perception of mobile devices as a tool for enjoying holidays and leisure time, as well as a useful substitute for traditional tourism tools (maps, guide books, video camera, etc.). Our results are aligned with the results of several studies that point out the emotional (passionate) use of smart phones [21].

The rest of the variables were not statistically significant. Our findings with regard to gender are consistent with several studies on Internet use that point out that gender differences have virtually disappeared [73]. Surprisingly, however, tourists' travel experience and previous knowledge about the destination were not significant variables. A possible interpretation of this result is that risk perception of mobile devices does not follow a learning process, but instead is consistent with an intrinsic consequence of pleasure, fun and unawareness of risk in the tourist experience.

The risk associated with dependence due to mobile device use seems to be more clearly perceived than the risk of privacy, according to the four regression models proposed. This presents an interesting finding that will have to be analysed in greater detail in future research, since there are no previous studies on this aspect. In addition, this study partially corroborates previous analyses that affirm that tourists perceive lack of privacy as a concern when using mobile devices [9]. Our analysis shows that the use of mobile devices for tourism purposes may be affected by the perception of risk, as risk is associated with lower experience satisfaction for tourists. Nevertheless, our results do not support other related studies that have pointed out that perceived risk is associated with a decrease in the value of smartphones usage [49], so it should be analysed further.

In addition, perceived privacy risk associated with the hedonic and future use of mobile devices was not found to be significant. In other words, tourists who were concerned about the risk of privacy when using mobile devices did not find their use more or less enjoyable and stated that they would use mobile devices in the future despite the risk. This finding is similar to conclusions drawn from other empirical studies regarding the use of smartphones among non-tourists [31]. We found that privacy risk was perceived to be higher when the use of mobile devices was for functional purposes, but the perceived privacy risk was lower when the use was for fun. Thus, this result suggests that tourists are more unaware of risks when enjoying the use of mobile phones than when they use them for practical purposes or as an instrument to solve a travel concern. It is also clear that low perceived privacy risk and high dependence on mobile devices combine to form high intention of future use values. In conclusion, because of tourists' high dependence on them, mobile devices form part of tourism instruments and will continue to do so in the future despite the perceived privacy risk.

Our study reveals several important implications for the sustainable management of smart tourism destinations in relation to the ethical use of mobile devices. First, tourists' perceived risk is a strategic issue, as it can negatively affect their satisfaction. Consequently, the sustainability of smart destinations depends on a balance between competitiveness-through the digital integration of technology - and ethical issues to ensure technology is used correctly (especially in tracking, marketing, location-based services or geolocalization). These issues can negatively affect privacy concerns and harm privacy rights, thus negatively impacting on tourist satisfaction.

We also discovered the existence of different tourist profiles regarding their perception of technology and mobile device usage. Some tourists are experienced technology users and technology is at the heart of their tourist experience, whilst other tourists are on the edge of the digital divide and are unskilled technology users. Smart tourism destination managers must bear in mind that an all-inclusive technological interpretation of destinations or a "compulsory" use of technology when visiting tourist locations might be counterproductive in terms of visitor satisfaction among unskilled mobile device users.

The result revealing that tourists have different risk perceptions related to the use of mobile devices while visiting a destination suggests that tourist managers should include risk variables when planning their destinations in order to gain competitiveness through sustainable practices. However, the analysis of perceived risk when using mobile devices has scarcely been taken into account from the point of view of sustainability. Therefore, a first research contribution of our work is that it can 
open up an interesting field of research into this issue. A second contribution of this article to the topic of sustainability is the identification of technological risk as a strategic indicator for smart tourism destinations that want to promote competitiveness through sustainability $[74,75]$. Consumers are influenced by a destination's sustainability conditions when deciding where to go on holiday [76]. An inappropriate use of technology, if it jeopardises consumers' privacy, can negatively impact on tourist satisfaction. The creation of indicators for technological risks would help to limit unsustainable practices such as the introduction of invasive marketing products, services or practices using mobile devices, which increases tourists' perceived risk.

Furthermore, destination stakeholders can approach their tourism strategies from a more sustainable point of view, enacting policies and drawing up actions that reduce perceived technological risk among visitors. Some good examples are destinations that promote technological disconnection during one's stay (for example, certain rural tourism destinations or establishments specialised in wellness or relaxation) or destinations targeting certain market segments interested in relaxation. Finally, is very important for smart tourism destinations to transmit an image that is not associated with technological risk if they want to achieve competitiveness based on parameters linked to quality and sustainability. Likewise, appropriate technological risk management can be used by smart tourism destinations to create a technology risk-free destination label, which would serve to differentiate them from competitors.

\section{Conclusions}

This study presents significant findings that will be able to help tourism managers to better focus on risk issues in smart tourism destinations when it comes to tourists' use of mobile devices. According to the results obtained, it can be concluded that tourists have different individual behaviours regarding their use of mobile devices. Thus, our first hypothesis was validated. In addition, a clearly different mobile device usage pattern can be distinguished among the four tourist groups identified in our cluster analysis. Even tourists that belong to the same generation (i.e., millennials) expressed a different response to the perceived risk associated with mobile device usage. This leads us to assume that a single digital tourist does not exist; thus, smart tourism destinations that try to differentiate from competitors by creating a digital tourism ecosystem need to offer different solutions and to adapt their strategy to satisfy the varied needs of their visitors. In future research, it will be necessary to expand our focus and to add new variables on the use of mobile devices-such as those related to emotional use- - to better understand the extent and magnitude of the differences between users.

While our first hypothesis was supported by this empirical study, others were not. Our second hypothesis (H2) was not supported, as privacy risk was not perceived as having a negative influence when evaluating the usefulness of mobile devices. Hypothesis H2.1 was also not supported, as dependence played a more fundamental role than privacy risk in the tourists' perceptions of the utility of mobile devices. Our final hypothesis H2.2 was not supported: a high level of perceived privacy risk increases satisfaction with the tourist experience originating from the use of smartphones, and a high level of perceived dependence risk also increases satisfaction.

If the results on the two types of risks analysed are compared, it can be observed that dependence has a more comprehensive role in explaining tourists' mobile device usage. The four regression models used indicate that it is statistically significant that an increase in dependence positively affects all aspects of mobile device use. Nevertheless, privacy risk is only statistically correlated with mobile devices utility value.

According to our results, tourists experience satisfaction is positively correlated with dependency on mobile devices but it is negatively correlated with privacy risk perception. Thus, the results of our research contribute to the inclusion of the risk variable in the smart tourism destination management agenda. For marketing purposes, these findings clearly advocate a market segmentation that introduces strategies that target tourists who are willing to accept the risk involved and, conversely, that omits tourists who are more sensitive to risk perception. It is important to emphasize that some individual 
sociodemographic (age) and technological skills of tourists are associated with risk perception. Thus, although dependence on mobile devices is associated with usefulness and fun for many tourists, it must be taken into account that, in some cases, there is a clear risk that marketing or information strategies that make inappropriate or intrusive use of privacy will negatively affect the tourists' experience at the destination.

Acknowledgments: This research was supported by Barcelona Provincial Council through the research project grant "Smart Tourism Destinations' Characterisation and Strategic Analysis of their Contribution to Competitiveness in the Barcelona Region's Tourism Destinations".

Author Contributions: Francesc González-Reverté and Pablo Díaz-Luque conceived and designed the statistical analysis, analyzed data and wrote the paper, Joan Miquel Gomis-López and Soledad Morales-Pérez help in writing some parts of the paper and revised the final version.

Conflicts of Interest: The authors declare no conflicts of interest.

\section{References}

1. Gretzel, U.; Fesenmaier, D.R.; O'Leary, J.T. The transformation of consumer behaviour. In Tourism Business Frontier; Buhalis, D., Costa, C., Eds.; Elsevier: Oxford, UK, 2006; pp. 9-18.

2. Lamsfus, C.; Wang, D.; Alzua-Sorzabal, A.; Xiang, Z. Going mobile: Defining context for on-the-go travelers. J. Travel Res. 2015, 54, 691-701. [CrossRef]

3. Wang, D.; Park, S.; Fesenmaier, D.R. The Role of Smartphones in Mediating the Touristic Experience. J. Travel Res. 2012, 51, 371-387. [CrossRef]

4. Womack, B. Attention, Attraction and Persuasion. Dissecting Soft Power. In Proceedings of the APSA 2009, Toronto, ON, Canada, 3-6 September 2009; Volume 41, pp. 951-977.

5. Neuhofer, B.; Buhalis, D.; Ladkin, A. Conceptualising Technology enhanced experiences. J. Destin. Mark. Manag. 2012, 1, 36-46.

6. Neuhofer, B.; Buhalis, D.; Ladkin, A. Smart technologies for personalized experiences: A case study in the hospitality domain. Electron. Mark. 2015, 25, 243-254. [CrossRef]

7. Sigala, M. Social media and crisis management in tourism: Applications and implications for research. Inf. Technol. Tour. 2012, 13, 269-283. [CrossRef]

8. Anuar, F.; Gretzel, U. Privacy concerns in the context of location-based services for tourism. In Proceedings of the ENTER Conference 2011, Innsbruck, Austria, 26-28 January 2011; ENTER Volume 2.

9. Gretzel, U. Intelligent systems in tourism. A social science perspective. Ann. Tour. Res. 2011, 38, 757-779. [CrossRef]

10. Gretzel, U. Travel in the Network: Redirected Gazes, Ubiquitous Connections and New Frontiers. In Post-Global Network and Everyday Life; Levina, M., Kien, G., Eds.; Peter Lang: New York, NY, USA, 2010; pp. 41-58.

11. Benyon, D.; Quigley, A.; O'Keefe, B.; Riva, G. Presence and digital tourism. AI Soc. 2014, 29, 521-529. [CrossRef]

12. Porter, M.E.; Heppelmann, J.E. How smart, connected products are transforming competition. Harvard Bus. Rev. 2014, 92, 64-88.

13. Koo, C.; Ricci, F.; Cobanoglu, C.; Okumus, F. Special issue on smart, connected hospitality and tourism. Inf. Syst. Front. 2017, 20, 699-703. [CrossRef]

14. Wang, D.; Xiang, Z.; Fesenmaier, D. Smartphone use in everyday life and travel. J. Travel Res. 2014, 55, 52-63. [CrossRef]

15. Tussyadiah, I.; Zach, F. The role of geo-based technology in place experiences. Ann. Tour. Res. 2011, 39, 780-800. [CrossRef]

16. Gutiérrez, M.; Vexo, F.; Thalmann, D. Stepping into Virtual Reality; Springer Science and Business Media: London, UK, 2008.

17. Dickinson, J.E.; Ghali, K.; Cherrett, T.; Speed, C.; Davies, N.; Norgate, S. Tourism and the smartphone app: Capabilities, emerging practice and scope in the travel domain. Curr. Issues Tour. 2014, 17, 84-101. [CrossRef]

18. Hannam, K.; Butler, G.; Paris, C.M. Development and key issues in tourism mobilities. Ann. Tour. Res. 2014, 44, 171-185. [CrossRef] 
19. White, N.R.; White, P.B. Home and away: Tourism in a connected world. Ann. Tour. Res. 2007, 34, 88-104. [CrossRef]

20. Rainie, L.; Wellman, B. Networked: The New Social Operating System; MIT-Press: Cambridge, MA, USA, 2012.

21. Lalicic, L.; Weismayer, C. The passionate use of mobiles phones among tourists. Inf. Technol. Tour. 2016, 16, 153-173. [CrossRef]

22. Lalicic, L.; Weismayer, C. Being passionate about the mobile when travelling. Curr. Issues Tour. 2016, 1-14. [CrossRef]

23. Dickinger, A.; Kleijnen, M. Coupons going wireless: Determination of consumer intention to redeem mobile coupons. J. Int. Mark. 2008, 22, 23-39. [CrossRef]

24. Tussyadiah, I. Social actor attribution to mobile phones: The case of tourists. Inf. Technol. Tour. 2014, 14, 21-47. [CrossRef]

25. Williams, A.M.; Baláž, V. Tourism, Risk Tolerance and Competences: Travel Organization and Tourism Hazards. Tour. Manag. 2013, 35, 209-221. [CrossRef]

26. Karl, M. Risk and uncertainty in travel decision-making: Tourist and destination perspective. J. Travel Res. 2016, 57, 1-18. [CrossRef]

27. Quintal, V.A.; Lee, J.A.; Soutar, G.N. Risk, Uncertainty and the Theory of Planned Behavior: A Tourism Example. Tour. Manag. 2010, 31, 797-805. [CrossRef]

28. Weber, E.U.; Bottom, W.P. Axiomatic Measures of Perceived Risk: Some Tests and Extensions. J. Behav. Decis. Mak. 1989, 2, 113-131. [CrossRef]

29. Mowen, J.C.; Minor, M. Consumer Behavior: A Framework; Prentice Hall: Upper Saddle River, NJ, USA, 2001.

30. Crompton, J.L. Structure of Vacation Destination Choice Sets. Ann. Tour. Res. 1992, 19, 420-434. [CrossRef]

31. Von Heijden, H.; Ogertschnig, M.; van der Gast, I. Effects of context relevance of perceived risk on user acceptance of mobile information services. In Proceedings of the European Conference on Information Systems (ECIS), Regensburg, Germany, 26-28 May 2005.

32. Fuchs, G.; Reichel, A. Tourist destination risk perception: The case of Israel. J. Hosp. Leisure Mark. 2006, 14, 83-108. [CrossRef]

33. Kahneman, D.; Tversky, A. Prospect Theory: An Analysis of Decision Making under Risk. Econometrica 1979, 47, 263-292. [CrossRef]

34. Schweer, J.M. Perceived leisure risk: Implications and interventions for therapeutic recreation in clinical settings. J. Expand. Horiz. Ther. Recreat. 1986, 1, 64-66.

35. Dowling, G.R.; Staelin, R. A model of perceived risk and intended risk-handling activity. J. Consum. Res. 1994, 21, 119-134. [CrossRef]

36. Gibson, H.; Yiannakins, A. Tourists roles: Needs and the lifecourse. Ann. Tour. Res. 2002, 29, 358-383. [CrossRef]

37. Reisinger, Y.; Mavondo, F. Cultural differences in travel risk perception. J. Travel Tour. Mark. 2006, $20,13-31$. [CrossRef]

38. Carr, N. An exploratory study of gendered differences in young tourists' perceptions of danger within London. Tour. Manag. 2001, 22, 565-570. [CrossRef]

39. Pizam, A.; Jeong, G.H.; Reichel, A.; van Boemmel, H.; Lusson, J.M.; Steynberg, L.; State-Costache, O.; Volo, S.; Kroesbacher, C.; Kucerova, J.; et al. The relationship between risk-taking, sensation-seeking and the tourist behavior of young adults: A cross-cultural study. J. Travel Res. 2004, 42, 251-260. [CrossRef]

40. Lepp, A.; Gibson, H. Sensation Seeking and Tourism: Tourist Role, Perception of Risk and Destination Choice. Tour. Manag. 2008, 29, 740-750. [CrossRef]

41. Roehl, W.S.; Fesenmaier, D.R. Risk perception and pleasure travel. An exploratory analysis. J. Travel Res. 1992, 30, 17-26. [CrossRef]

42. Kaasinen, E. User needs for location-aware mobile services. Pers. Ubiquitous Comput. 2002, 7, 70-79. [CrossRef]

43. Minch, R. Privacy issues in location-awareness mobile devices. In Proceedings of the 37th Hawaii International Conference on System Sciences, Big Island, HI, USA, 5-8 January 2004.

44. Turkle, S. Alone Together: Why We Expect More from Technology and Less from Each Other; Basic Books: New York, NY, USA, 2011.

45. Smith, H.J.; Milberg, S.J.; Burke, S.J. Information privacy: Measuring individual concerns about organizational practices. MIS Q. 1996, 20, 167-196. [CrossRef] 
46. Mahmood, T.; Ricci, F.; Venturini, A.; Höpken, W. Adaptive recommender systems for travel planning. In Information and Communication Technologies in Tourism 2008; O'Connor, W., Höpken, W., Gretzel, U., Eds.; Springer: Vienna, Austria, 2008; pp. 191-202.

47. Ackerman, M.S.; Cranor, L.F.; Reagle, J. Privacy in E-commerce: Examining user scenarios and privacy preferences. Proceedings of Electronic Commerce, Denver, CO, USA, 3-5 November 1999; pp. 1-8.

48. Snekkenes, E. Concepts for personal location privacy policies. In Proceedings of the 3rd ACM Conference on Electronic Commerce, Tampa, FL, USA, 14-17 October 2001; pp. 48-57.

49. Barkuus, L.; Dey, A. Location-based services for mobile telephony: A study of user's privacy concerns. In Proceedings of the INTERACT, 9th IFIP TC13 International Conference of Human-Computer Interaction, Zürich, Switzerland, 1-5 September 2003; pp. 709-712.

50. Featherman, M.S.; Pavlou, P.A. Predicting e-services adoption: a perceived risk facets perspective. Int. J. Hum.-Comput. Stud. 2003, 59, 451-474. [CrossRef]

51. Kim, L.H.; Kim, D.J.; Leong, J.K. The effect of perceived risk on purchase intention in purchasing airline tickets online. J. Hosp. Leisure Mark. 2005, 13, 33-53. [CrossRef]

52. Kim, L.H.; Qu, H.; Kim, D.J. A study of perceived risk and risk reduction of purchasing air-tickets online. J. Travel Tour. Mark. 2009, 26, 203-224. [CrossRef]

53. Park, S.; Tussyadiah, I.P. Multidimensional facets of perceived risk in mobile travel booking. J. Travel Res. 2016, 56, 854-867. [CrossRef]

54. IDESCAT. Anuari Estadístic de Catalunya; Generalitat de Catalunya: Barcelona, Spain, 2017.

55. Duró, J.A.; Rodríguez, D. Barcelona como municipio turístico: Algunos datos evolutivos y elementos de future. Doc. Anàl. Geogr. 2015, 61, 507-538. [CrossRef]

56. Cambra de Comerç de Barcelona. El Potencial Econòmic del Turisme a l'Alt Penedès, el Baix Llobregat i el Garraf; Cambra de Comerç de Barcelona: Barcelona, Spain, 2010.

57. Ajuntament de Calella. Pla Estratègic Integral de Calella 2010; Ajuntament de Calella: Calella, Spain, 2016.

58. Beinat, E. Privacy and location-based: Stating the policies clarely. Geoinformatics 2001, 4, 14-17.

59. Hubert, M.; Blut, M.; Brock, C.; Backhaus, C.; Eberhardt, T. Acceptance of smartphone-based mobile shopping: Mobile benefits, customer characteristics, perceived risks, and the impact of application context. Psychol. Mark. 2017, 34, 175-194. [CrossRef]

60. Ruiz, C.; Sanz, S.; Aldás, J. Drivers and barriers in online tickets purchaising. J. Air Transp. Manag. 2009, 15, 294-298. [CrossRef]

61. White, M.P.; Eiser, J.R.; Harris, P.R. Risk perception of mobile phone use while driving. Risk Anal. 2004, 24, 323-334. [CrossRef] [PubMed]

62. Fournier, S.; Mick, D.G. Rediscovering satisfaction. J. Mark. 1999, 63, 5-23. [CrossRef]

63. Arnould, E.J.; Price, L.L. River magic: Extraordinary experience and the extended service encounter. J. Consum. Res. 1993, 20, 24-45. [CrossRef]

64. Miao, L.; Lehto, X.; Wei, W. The hedonic value of hospitality consumption: Evidence from Spring Break experiences. J. Hosp. Mark. Manag. 2014, 23, 99-121. [CrossRef]

65. Tasci, A.; Ko, Y. A fun-scale for understanding the hedonic value of a product: The destination context. J. Travel Tour. Mark. 2016, 33, 162-183. [CrossRef]

66. Kim, D.Y.; Park, J.; Morrison, A.M. A model of travel acceptance of mobile technology. Int. J. Tour. Res. 2008, 10, 393-408. [CrossRef]

67. Aguiló-Pérez, E.; Rosselló-Nadal, J. Host Community Perceptions. A cluster Analysis. Ann. Tour. Res. 2005, 32, 925-944. [CrossRef]

68. Fredline, E.; Faulkner, B. Host community reactions. A cluster analysis. Ann. Tour. Res. 2000, $27,763-784$. [CrossRef]

69. Hair, J.; Anderson, R.; Tathem, R.; Black, W. Multivariate Data Analysis; Prentice Hall: Upper Saddle River, NJ, USA, 1998.

70. Koo, C.; Chung, N.; Kim, H.W. Examining explorative and exploitative uses of smartphones: A user competence perspective. Inf. Technol. People 2015, 28, 133-162. [CrossRef]

71. Chung, N.; Tyan, I.; Han, H. Enhancing the smart tourism experience through geotag. Inf. Syst. Front. 2017, 19, 731-742. [CrossRef]

72. Persaud, A.; Azhar, I. Innovative mobile marketing via smartphones: Are consumers ready? Mark. Intell. Plan. 2012, 30, 418-443. [CrossRef] 
73. Phillip, M. V.; Suri, R. Impact of gender differences on the evaluation of promotional emails. J. Advert. Res. 2004, 44, 360-368. [CrossRef]

74. Angelkova, T.; Koteski, C.; Jakovlev, Z.; Mitrevska, E. Sustainability and competitiveness of tourism. Procedia-Soc. Behav. Sci. 2012, 44, 221-227. [CrossRef]

75. Dweyer, L.; Chulwon, K. Destination competitiveness: Determinants and indicators. Curr. Issues Tour. 2003, 5, 369-414. [CrossRef]

76. Miller, G. The deveopment of indicators for sustainable tourism: Results of a Delphi survey on tourism researchers. Tour. Manag. 2001, 22, 351-362. [CrossRef]

(C) 2018 by the authors. Licensee MDPI, Basel, Switzerland. This article is an open access article distributed under the terms and conditions of the Creative Commons Attribution (CC BY) license (http:// creativecommons.org/licenses/by/4.0/). 